\title{
Partial Edentulism in Patients Visiting the Dental Out-Patient Department at the Tertiary Care Centre in the Eastern Part of Nepal
}

\author{
Shrestha $\mathrm{P}^{1^{*}}$, Bhagat $\mathrm{T}^{2}$ \\ ${ }^{1}$ Tutor, Department of Prosthodontics, National Academy of Medical Sciences, Kathmandu, Nepal \\ ${ }^{2}$ Associate Professor, Department of Public Health Dentistry CODS, BPKIHS, Dharan, Nepal.
}

\begin{abstract}
Introduction: Partial edentulism is an irreversible condition resulting from various dental diseases like dental caries and periodontal lesions. Loss of teeth produces deleterious effects on masticatory function, phonetics, facial appearance and comfort of the patients. If not restored on time, it can lead to pathological changes in vertical dimension, occlusion and temporomandibular joint.

Methods: This study was conducted in the department of Prosthodontics, CODS, BPKIHS from September 2015 to March 2016. All patients above the age of 14 years presenting with partial loss of dentition and willing to give informed consent were included in the study. Data regarding age, gender, missing teeth, cause of permanent tooth loss and age of first permanent tooth loss were collected from 750 patients.

Results: Dental caries was the major cause of tooth loss accounting for $60.5 \%$ of the study population followed by periodontal disease (14.0\%) and trauma (11.9\%). First permanent tooth loss was highest in the age group of 35-44 years $(22.9 \%)$. The most common type of partial edentulism was found to be Kennedy's class III followed by class IV, class I and class II in both the arches.

Conclusions: The most common cause of permanent tooth loss was dental caries in the study population. The first permanent tooth loss was found to be highest in age group 35-44 years. The most common type of partial edentulism was the Kennedy's class III in both the arches.
\end{abstract}

Key words: Dental caries; Edentulism; Kennedy's classification

\section{Introduction}

$\mathrm{P}$ artial edentulism, defined as the loss of 1-15 teeth on a jaw, is caused by periodontal diseases, caries, oro-facial trauma and birth defects $^{1-5}$. Edentulism is associated with low income, poor oral hygiene and dietary habits, use of tobacco and alcohol, illiteracy and inadequate oral health services ${ }^{4,6,7}$. Long term partial edentulism leads to occlusal discrepancies, tooth migration, and temporomandibular joint disorders. It also can lead to low intake of fruits and vegetables in-turn affecting general health and quality of life. ${ }^{5,8}$

\footnotetext{
*Corresponding Author

Dr. Pragya Shrestha, Tutor, Department of Prosthodontics, National Academy of Medical Sciences, Kathmandu, Nepal.

Email:prags.bp@gmail.com
}

Etiology of partial edentulism in our region is not well documented. Knowing the etiology of partial edentulism helps in identifying preventive strategies and prosthetic needs.

The present study aims to identify the causes of permanent tooth loss, age of first permanent tooth loss, and type of partial edentulism present in patients visiting the dental OPD of tertiary care centre in Eastern Nepal.

\section{Methods}

This cross sectional study was conducted in the department of Prosthodontics, CODS, BPKIHS from September 2015 to March 2016. All patients above the age of 14 years reporting to the department presenting with partial loss of dentition were invited to participate in the study. 
Those willing to participate were required to sign informed consent. The data regarding age, gender, missing teeth, cause of permanent tooth loss and age of first permanent tooth loss were collected from 750 patients using structured data collection form. Inclusion criteria were partially edentulous patients with age above 14 years. An exclusion criterion was patients not willing to give written informed consent. Consecutive sampling technique was followed and the sample size was calculated as 750 .

\section{Methodology}

All patients reporting to the department of Prosthodontics presenting with partial loss of dentition within the study period of five months were taken as sampling unit. The participants were explained about the study by the principal investigator and written informed consent was obtained. A brief history was taken and recorded in the case record sheet followed by clinical examination. The findings were then entered in the work proforma. Training and calibration of the examiner were done in the department prior to the start of the study. At the end of stipulated time period, the data were entered into a Microsoft 2007 Excel sheet and descriptive statistical analysis was done using SPSS version 11.5 by age, gender, type of partial edentulism and cause and age of first permanent tooth loss.

\section{Results}

The age of study population ranged between $15-78$ years. Out of 750 study population, 346 (46.1\%) were male and 404 (56.9\%) were females. (Table 1)

Dental caries was found to be the most common cause of tooth loss (60.5\%) followed by periodontal $(14 \%)$, trauma $(11.9 \%)$, caries and periodontal $(10.4 \%)$, caries and trauma $(2.3 \%)$, others $(0.7 \%)$ and periodontal and trauma $(0.3 \%)$ (Table 2$)$.
First permanent tooth loss was found to be maximum in the age group of 35-44 years (22.9\%) followed by $45-54$ years $(20.4 \%)$, $25-34$ years $(19.2 \%)$, 55-64 years $(16.4 \%)$, $14-24$ years $(15.7 \%), 65-74$ years $(4.5 \%)$ and $75-84$ years $(0.3 \%)$. Loss of permanent tooth at the very young age group $(<14$ years) was $0.5 \%$. (Figure 1 )

$60 \%$ of the study population has partial edentulism present on the maxillary arch. The most common type of partial edentulism present in the maxillary arch was Kennedy's class III (26.4\%) followed by class III modification 1 $(6.5 \%)$, class IV $(6.4 \%)$, class I $(5.3 \%)$, class II $(4.5 \%)$.

$66 \%$ of the study population has partial edentulism present in the mandibular arch. The most common type of partial edentulism present in the mandibular arch was found to be Kennedy's class III (21.3\%) followed by class III modification $1(10.9 \%)$, class IV $(9.9 \%)$, class I (8.7\%), class II (5.6\%). (Table 3, Table 4)

Table 1: Age and Gender Distribution

\begin{tabular}{|l|c|c|}
\hline \multirow{2}{*}{ Age range } & \multicolumn{2}{|c|}{ Gender distribution } \\
\cline { 2 - 3 } & Male & Female \\
\hline $15-78$ years & 346 & 404 \\
\hline
\end{tabular}

Table 2: Causes of Tooth Loss

\begin{tabular}{|c|l|c|}
\hline S.N. & Causes of tooth loss & Percentage \\
\hline 1 & Caries & 60.5 \\
\hline 2 & Caries and periodontal & 10.4 \\
\hline 3 & Caries and trauma & 2.3 \\
\hline 4 & Trauma & 11.9 \\
\hline 5 & Periodontal & 14.0 \\
\hline 6 & Periodontal and trauma & 0.3 \\
\hline 7 & Others & 0.7 \\
\hline
\end{tabular}

Table 3: Arch Distribution

\begin{tabular}{|c|c|c|}
\hline Arch & Maxillary Arch & Mandibular Arch \\
\hline Number & 450 & 495 \\
$(\%)$ & $(60 \%)$ & $(66 \%)$ \\
\hline
\end{tabular}


Table 4: Type of Edentulism in Maxillary and Mandibular Arches

\begin{tabular}{|c|c|c|c|}
\hline S.N. & Kennedy's class & $\begin{array}{c}\text { Maxillary Arch } \\
(\mathbf{\%})\end{array}$ & $\begin{array}{c}\text { Mandibular Arch } \\
(\mathbf{\%})\end{array}$ \\
\hline 1 & Class I & 5.3 & 8.7 \\
\hline 2 & Class I mod 1 & 2.1 & 1.6 \\
\hline 3 & Class I mod 2 & 0.8 & 0.1 \\
\hline 4 & Class I mod 3 & 0.1 & - \\
\hline 5 & Class II & 4.5 & 5.6 \\
\hline 6 & Class II mod 1 & 3.2 & 5.5 \\
\hline 7 & Class II mod 2 & 2.1 & 1.2 \\
\hline 8 & Class II mod 3 & 0.5 & 0.3 \\
\hline 9 & Class III & 26.4 & 21.3 \\
\hline 10 & Class III mod 1 & 6.5 & 10.9 \\
\hline 11 & Class III mod 2 & 1.6 & 0.7 \\
\hline 12 & Class III mod 3 & 0.1 & 0.3 \\
\hline 13 & Class IV & 6.4 & 9.9 \\
\hline 14 & Class IV mod 1 & 0.1 & - \\
\hline
\end{tabular}

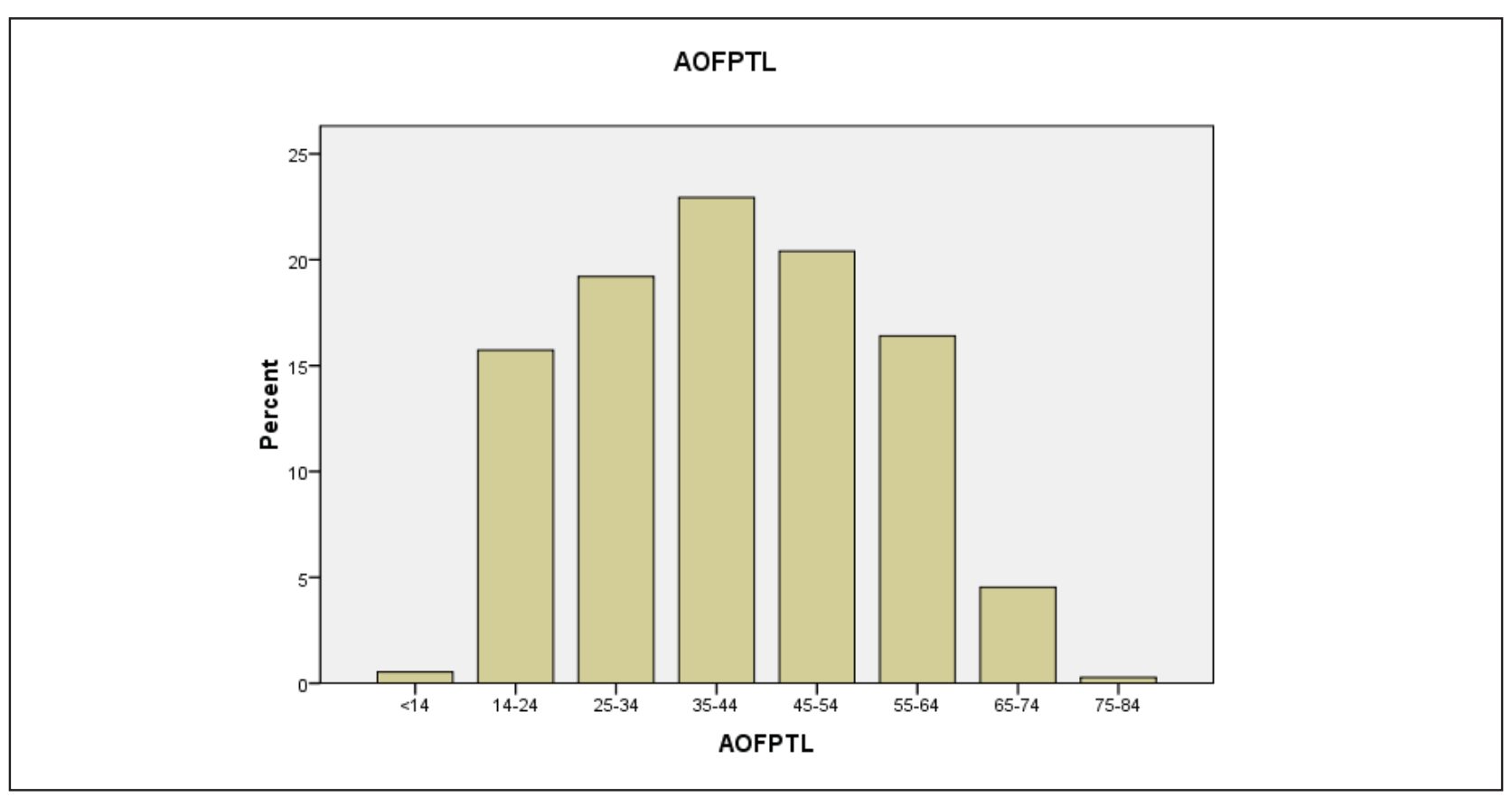

Figure 1: Age of first permanent tooth loss (AOFPTL) in years

\section{Discussion}

This study revealed that partial edentulism was more common in females than in males which is consistent with the study carried out by Abdurahiman VT et al, Naveed $\mathrm{H}$ et al, Sapkota B et al, Patel JY et al. ${ }^{9-12}$ Main cause of tooth loss was found to be dental caries $(60.5 \%)$ followed by periodontal disease
(14\%) which is in agreement with the findings of studies carried out by Akinboboye B et al, Muneeb A et al. ${ }^{13,14}$ First permanent tooth loss was found to be maximum in the age group of 35-44 years $(22.9 \%)$. This could be due to lack of awareness about dental diseases and consequences of tooth loss, inability to afford the cost of treatment and lack of motivation 
to save teeth and unavailability of treatment facilities. Mandibular arch (66\%) was affected more than the maxillary arch $(60 \%)$ which is consistent with findings of other studies ${ }^{10,12,15}$. Mandibular first molar is the first permanent tooth to erupt in the oral cavity at the age of around 6 years. Therefore it is the most affected tooth in the oral cavity. The most common type of edentulism was Kennedy's class III both in maxilla and mandible which is in agreement with the various studies conducted by D'Souza KM et al, Naveed $\mathrm{H}$ et al, Sapkota B et al, Patel JY et al, Muneeb A et al, Bharathi $M$ et al, Charyeva OO et al, Shinawi LA ${ }^{4}, 10-12,14,16-18$. The second most common type of edentulism was Kennedy's class IV both in maxilla and mandible. Similar finding was found in the study conducted by Munneb A et a ${ }^{14}$. The main reason for Kennedy's class IV partial edentulism was trauma and it seemed quite common in our part of the world. Kennedy's class II edentulism was least common in the present study while Kennedy's class I was the least common in the study conducted by Munneeb A et al. ${ }^{14}$ and Kennedy's class IV was the least prevalent in studies done by Patel JY et al, Bharathi M et al and Charyeva $\mathrm{OO}$ et al. ${ }^{12,16,17}$

\section{Limitation of this study}

The main limitation of this study is that the study population is not representative of the general population since we recruited subjects from patients already attending a dental OPD. Hence the results may not be a true indication of distribution of pattern partial edentulism in the Nepalese population. Future studies should address this gap and also explore the subject's socioeconomic indictors, access to health care and attitude towards dental treatments.

\section{Conclusions}

The most common cause of permanent tooth loss was dental caries and first permanent tooth loss was highest in age group of 35-44 years(22.9\%).
Mandibular arch was more affected than the maxillary arch. The most common type of partial edentulism was Kennedy's class III and least common was Kennedy's class II in both the arches.

\section{Acknowledgements}

I would like to acknowledge Dr. Pramita Suwal and Prof. Dr. R. K. Singh for their support during the study of this work.

\section{References}

1. Bratu E, Bratu D, Antonie S. Classification system for partial edentulism. J Oral Health Dent. 2007; 4:50-5.

2. World Oral Health Report 2003 [Internet]. World Health Organization; [cited 2017Dec11]. Available from: http://www.who.int/oral_health/ publications/world-oral-health-report-2003/en/

3. Fox $\mathrm{CH}$. Oral health [Internet]. Lancet;[cited 2017Dec17]. Available from: http://www.thelancet.com/journals/ lancet/article/PIIS0140-6736(09)60394-9/ fulltext

4. D'Souza KM, Aras M. Association between socio-demographic variables and partial edentulism in the Goan population: an epidemiological study in India. Indian J Dent Res 2014;25:434-8.

5. National Oral Health Policy 2004. [Internet] Available from: http://healthlinknepal.org/ uploads/files/National $\% 20$ Oral $\% 20$ Health $\% 20$ Policy.pdf

6. Petersen PE, Bourgeois D, Ogawa H, EstupinanDay S, Ndiaye C. The global burden of oral diseases and risks to oral health. Bull World Health Organ 2005;83:661-9.

7. Batista MJ, Lawrence HP, de Sousa MLR. 2014. Impact of tooth loss related to number and position on oral health quality of life among adults. Health QualLife 2014;12:165.

8. Emami E, de Souza RF, Kabawat M, Feine JS. The impact of edentulism on oral and general health. Int J Dent2013;2013:1-7.

9. Abdurahiman VT, Khader MA, Jolly SJ. Frequency of partial edentulism and awareness to restore the same: A cross sectional study in 
the age group of 18-25 years among Kerala student population. J Indian Prosthodont Soc2013;13:461-5.

10. Naveed H, Aziz MS, Hassan A, Khan W, Azad AA. Patterns of partial edentulism among armed forces personnel reporting at Armed Forces Institute of Dentistry Pakistan. Pak Oral Dent J 2011;31:217-21.

11. Sapkota B, Adhikari B, Upadhaya C. A Study of Assessment of Partial Edentulous Patients Based on Kennedy's Classification at Dhulikhel Hospital Kathmandu University Hospital. Kathmandu Univ Med J 2013;11:325-7.

12. Patel JY, Vohra MY,Hussain JM. Assessment of Partially Edentulous Patients Based on Kennedy's Classification and its Relation with gender predilection. IntJSciStudy2014;2:32-6.

13. Akinboboye B, Azodo C, Soroye M. Partial edentulism and unmet prosthetic needs amongst young adult Nigeria. Odontostomatol Trop. 2014;37:47-52.
14. Muneeb A, Mohsin B, Jamil B. Causes and pattern of partial edentulism / exodontia and its association with age and gender : Semi rural population, Baqai dental college, Karachi, Pakistan. IntDent JStudents' Res2013;1:13-8.

15. Curtis DA, Curtis TA, Wagnild GW, Finzen FC. Incidence of various classes of removable partial dentures. J Prosthet Dent 1992;67:664-7.

16. Bharathi M, Babu KRM, Reddy G, Gupta N, Misuria A, Vinod V. Partial Edentulism based on Kennedy's Classification: An Epidemiological study. J Contemp Dent Pract 2014;15:229-31.

17. Charyeva, OO, Altynbekov KD, Nysanova BZ. Kennedy classification and treatment options: a study of partially edentulous patients being treated in a specialized prosthetic clinic. $\mathrm{J}$ Prosthodont 2012;21:177-80.

18. Shinawi LA. Partial edentulism: a five year survey on the prevalence and pattern of tooth loss in a sample of patients attending King Abdul Aziz University - Faculty of Dentistry. Life Sci J 2012;9:2665-71. 